\title{
Application of ESEM and Optical Microscopy in Analyzing Textile Specimens from Various Archaeological Sites
}

\author{
A.J. Thompson*, V. Wimberley*, M. Simon** \\ * The University of Alabama, Department Clothing, Textiles, and Interior Design \\ Tuscaloosa, AL 35487 \\ ** Illinois Transportation Archaeological Research Program, University of Illinois, Urbana- \\ Champaign
}

Textile specimens found in Eastern and Midwestern North America archaeological sites are often carbonized or pseudomorphic fragments. Many of these textiles retain very little evidence of their original color and may appear black or brown because of the charring or fossilizing process. For this reason, characterizing the structure of the textile fragment by microscopy imaging techniques can be one of the only viable means to gather information. In this study, three particular cases have been characterized using ESEM and Optical Microscopy to determine fiber, yarn, and fabric construction. In each case, cultural information was derived from that analysis.

The Moundville site in Alabama is considered a late prehistoric location of human activity. The specimens addressed here are mainly from Moundville II (AD 1250-1400) and III (AD 14001550) time periods. Mounds $\mathrm{W}$ and $\mathrm{R}$ along with the Rhodes site were the locations where textile specimens were gathered. Textile fragments from Mound $\mathrm{W}$ and $\mathrm{R}$ were charred, small in size $\left(<10 \mathrm{~cm}^{2}\right)$, and were brittle. The Rhodes site provided a copper breast plate with preserved textile remains in the form of pseudomorphs. Only charred textiles provided information on the fiber types. Yarn diameter and twist indicated boundaries between residential and apparently moderate elite burials at Moundville [1].

The second example in textile fragment identification is from a black, open weave fabric specimen from a $19^{\text {th }}$ century historic site on the University of Alabama campus, Figure 1 . The fiber was identified as cotton by the characteristic convolutions along the longitudal axis and lima-bean shaped cross-section. Note, fibers are not highly oriented in one direction for yarn formation. It appears that these yarns were made from carded fibers as opposed to combed. The twist to form the yarn has fewer turns per inch which makes the yarns less compact. The weave was a simple plain weave. The thread count of this fabric was 30 yarns per centimeter in the vertical direction and 20 yarns per centimeter in the horizontal direction. There are no construction features that could be used to identify whether it was a fragment of a garment or a household textile. The spacing of the vertical and horizontal yarns of this specimen indicated a lower thread count consistent with a either a muslin, gauze or cheesecloth fabric. This specimen was compared to other fabrics of the same weave and fiber content from artifacts of the mid to late $19^{\text {th }}$ century for determination of possible end uses [2]. 
The final example where structure analysis was performed came from specimens from the excavations at the Janey B. Goode site, located in the American Bottom region of Illinois. This site yielded carbonized textile remains from two pit features dating to the Terminal Late Woodland period (circa A.D. 650) and from one pit feature dating to the Mississippian period (A.D. 1100). The remains comprise both twisted or braided cordage pieces and actual twined textile fragments ranging in size from $2 \times 3 \mathrm{~cm}$ to over $9 \times 9 \mathrm{~cm}$. Four different twining techniques are represented: two types of compact twining and two types of space twining. All textiles appear to be constructed of bast fibers, probably from the outer part of herbaceous plant stems. The textiles are similar to those described from other Midwestern sites dating to the Woodland and Mississippian periods, reflecting the existence of a widespread fiber industry [3].

\section{References:}

[1] V.Wimberley and A.J. Thompson Textile: The J of Cloth and Culture 8(3)(2010) 348-367. [2] V. Wimberley and A.J. Thompson $65^{\text {th }}$ Annual Meeting of the International Textile and Apparel Association National Meeting, Chicago, Illinois(2008).

[3] A.J. Thompson and M. Simon Mid-Continental J. of Arch 33(2) (2008) 155-181.
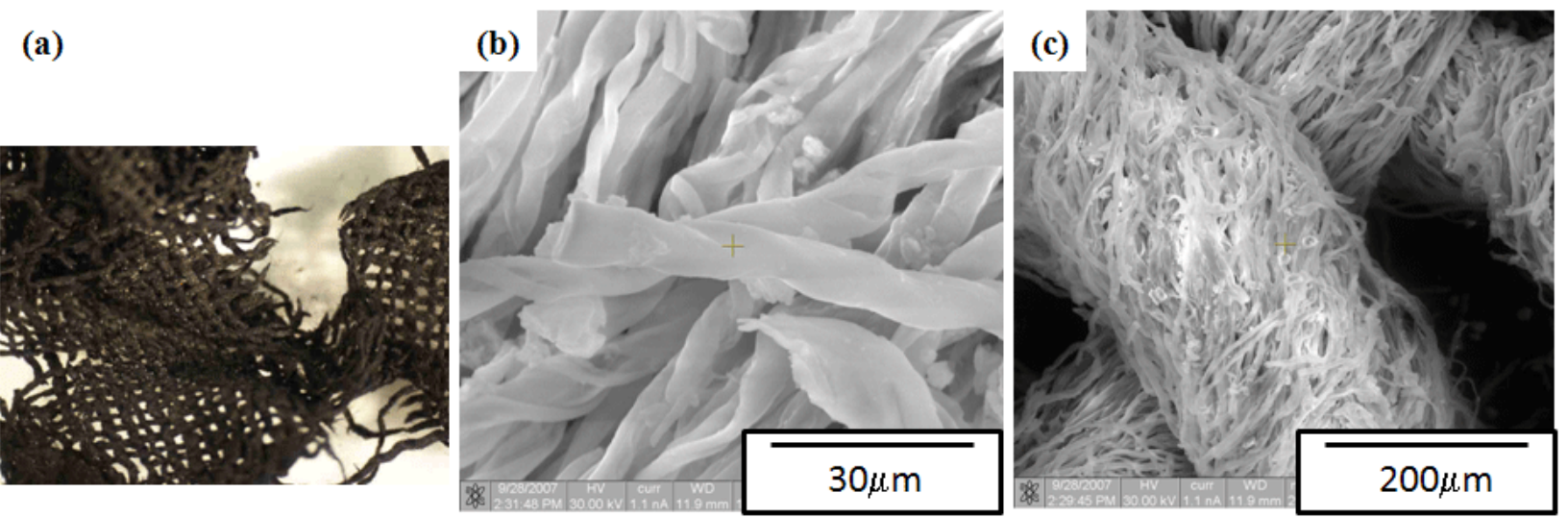

Figure 1: (a) Overview of $19^{\text {th }}$ Century UA textile specimen captured at $0.67 \mathrm{X}$. (b) Lima bean cross section indicative of cotton. (c) Magnified micrograph of fibers within the yarns. Note that the fibers are twisted clockwise. Images are taken from reference [2]. 